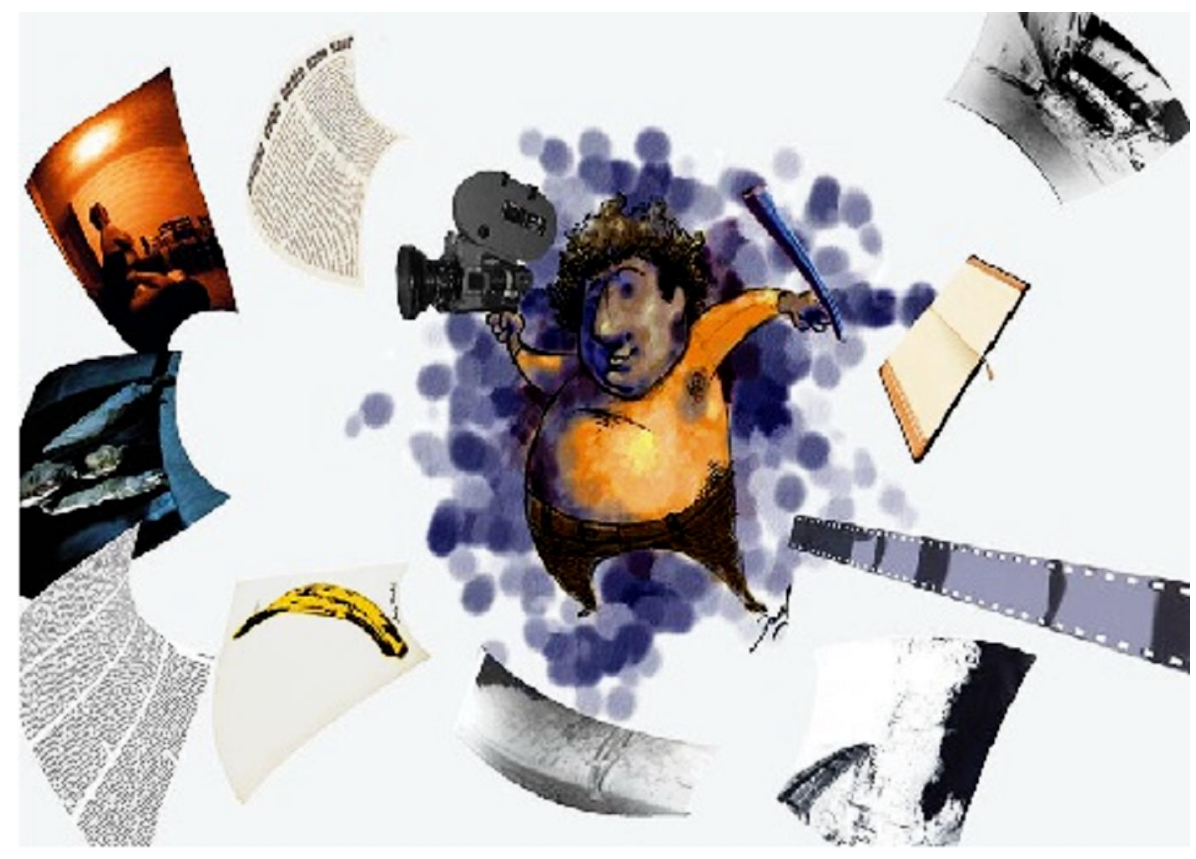

David Mussel

\title{
Recursos cinematográficos na prosa pop de André Sant'Anna
}

\section{Antonio Eduardo S. Laranjeira}

Graduado em Letras pela Universidade Federal da Bahia. Mestre e Doutorando em Teoria Literária. Desenvolve pesquisa sobre Literatura Pop Contemporânea.

\section{Resumo}

No discurso literário pop, é notável a fusão de linguagens e referências. Considerando-se o texto pop pós-moderno de André Sant'Anna como objeto, é possível observar de que maneira os recursos cinematográficos são utilizados no processo de construção das narrativas "Aquarius", conto publicado em Amor e outras histórias, e Sexo, romance subseqüente. Com base nos estudos de Marinyze Prates de Oliveira sobre a ficção de João Gilberto Noll, a partir da sistematização do uso dos recursos cinematográficos na literatura contemporânea, é possível afirmar que a prosa pop de André Sant'Anna é perpassada pela presença de estratégias narrativas do cinema.

Palavras-chave: literatura pop, cinema, André Sant'Anna. 


\section{Introdução}

As relações entre cinema e literatura têm sido alvo de reflexão por parte de diversos teóricos, tanto no âmbito dos estudos sobre a linguagem cinematográfica quanto no contexto dos estudos literários. Segundo Jean Epstein, a literatura moderna encontra-se saturada de linguagem cinematográfica; do mesmo modo, o próprio cinema tem assimilado muitos aspectos da literatura(1). A despeito das particularidades de cada linguagem, é possível admitir que haja freqüentes entrecruzamentos, no que se refere à relação entre as duas artes: "entre a superfície em branco da página e o espaço vazio da tela há laços mais estreitos do que nos é dado suspeitar à primeira vista" (2) .

A frase anterior é extraída de um dos capítulos do estudo sobre a produção de João Gilberto Noll realizado por Marinyze Prates de Oliveira, "Literatura e cinema: vias de mão dupla". Seu título sugestivo aponta para a dinâmica e não rara aproximação entre as duas artes. Não se trata, entretanto, de compreender tal intercâmbio como algo recente, mas de examiná1o, considerando-se que, desde antes da existência do cinema, recursos hoje ditos cinematográficos já podiam ser divisados em textos literários. A aproximação entre as duas artes não se dá, todavia, apenas pelo uso de determinados recursos, mas também por meio da citação, da referência aos ícones e da tradução intersemiótica.

É notável o fato de que, na contemporaneidade, a mescla de linguagens tenha se tornado recorrente. Isso não é, entretanto, privilégio da literatura, mas de todo o campo das artes. "Em nenhum outro momento de sua história, porém, ele [o homem] se viu emaranhado em uma pluralidade tão excepcional de linguagens quanto na contemporaneidade"(3). O desenvolvimento tecnológico - incluído aqui o surgimento do cinema e da televisão - desempenhou um papel relevante para aguçar e reconfigurar os hábitos perceptivos: diferentes formas de captar e olhar o mundo despontam, então, como possibilidades estéticas alternativas.

Não é sem tensões, contudo, que os laços entre cinema e literatura são estabelecidos. Quando da aparição das novas tecnologias, as duas artes, pode-se afirmar, pertenciam a pólos opostos: o da cultura de massa e o da cultura erudita. Quanto à arte literária, observa-se uma preocupação em resistir às influências nocivas de um novo meio de expressão considerado sem aura. Por outro lado, o cinema, em busca de legitimação no campo das artes, tende a aproximar-se da literatura - sobretudo da sua narratividade - com vistas a 
obter uma consagração que somente as artes tradicionais possuíam. As adaptações de textos literários canônicos e a proposta da existência de um cinema autoral foram formas encontradas para conferir uma aura ao filme.

Em torno dessas tensões é que se inscreve a apropriação dos recursos cinematográficos pela literatura moderna e, sobretudo, pela contemporânea. Os modernistas brasileiros "encontraram no horizonte técnico que despontava em nosso país (e já se cristalizara na Europa) um vasto campo de tematização e uma importante fonte de recursos capazes de alargar as possibilidades do dizer literário"(4). Em sintonia com o presente e sempre ansiando pelo novo, a literatura moderna e modernista ampliava os horizontes estéticos, superpunha a estética cinematográfica ao texto literário, como sugere Jean Epstein. Mas se a prosa do início do século XX inova, ao incorporar procedimentos cinematográficos, instaurando uma ruptura frente ao cânone literário, não chega a assumir o status de cultura de massa.

Desse status, aproxima-se a literatura pop. Conforme Evelina Hoisel, no discurso literário pop, é marcante a sintonia com outras artes(5), o que se justifica pela sua proximidade com a pop art. O fenômeno pop, ponto de encontro entre a arte culta e a comunicação de massa, ao lançar mão de um repertório de imagens populares, oriundas da cultura urbana moderna, pode ser compreendido como uma estética da consumibilidade. Nessa perspectiva, tende a dessacralizar o caráter da obra de arte, extraindo sua aura (ou o que dela restava). A experiência estética passa, assim, a valorizar mais o contato, a participação e o divertimento.

É nesse ponto que o diálogo com o cinema se intensifica. As alusões e apropriações dos mass media pela literatura pop são aspectos destacados por Hoisel, em seu estudo sobre a produção de José Agrippino de Paula - PanAmérica e Nações Unidas. Essa interação parece atingir o paroxismo no fato de que, em PanAmérica, não somente a temática é a elaboração de um filme, mas também as técnicas do cinema são utilizadas na construção da narrativa. O fluxo de imagens visuais próprias ao cinema é tão intenso em PanAmérica que, segundo Hoisel, o leitor precisa "ter em mente uma tela de cinema para visualizar toda a riqueza de expressão plástica em movimento compactada no texto" (6).

A linguagem e a temática são aspectos sobre os quais se debruça Décio Torres Cruz em o pop: literatura, mídia e outras artes(7). Ao desenvolver as questões abordadas por Hoisel, Cruz realiza um mapeamento das narrativas pop, situando-as em dois períodos distintos: num primeiro momento, detém-se sobre os textos das décadas de 1950 e 1960; num segundo, refere-se à 
produção dos anos 1970 e 1980. Nessa trajetória, o discurso literário pop aparece marcado por uma temática em que o mundo do cinema, das estrelas de Hollywood e da cultura urbana e industrial ocupa papel de destaque. A linguagem, por sua vez, é caracterizada pela ruptura em relação às regras e pela busca por novas formas, em que as técnicas cinematográficas (como o zoom e os closes) são incorporadas à prosa pop.

Os dois estudos mencionados sinalizam para a relação entre a literatura pop e o cinema. Todavia, percebe-se que, em nenhum deles, há um maior detalhamento no que concerne à apropriação dos recursos cinematográficos pelo texto literário. Em E a tela invade a página, (8)procede a uma leitura de Hotel Atlântico, de João Gilberto Noll, e sistematiza o uso dos recursos cinematográficos na literatura contemporânea. A partir desse referencial teórico, é possível observar como tais recursos são incorporados pela literatura pop brasileira contemporânea. Elegendo-se como objeto de estudo o conto "Aquarius"(9)e o romance Sexo(10), de André Sant'Anna, pretende-se discutir de que maneira ocorre a incorporação do cinema à literatura pop produzida a partir da década de 90 .

\section{"Aquarius": a câmera em movimento}

Em "Aquarius", conto publicado no volume Amor e outras histórias, o movimento é incessante. Se fosse necessária uma sinopse do conto, das múltiplas possibilidades, uma delas seria tratá-lo como um curta-metragem composto por uma seqüência de vários planos, sobretudo médios e de detalhe, culminando com um travelling conclusivo para trás. A cena transcorre numa praia repleta de pessoas, sem diálogos, o que confere ao olhar do narrador um papel de destaque. O narrador, como uma câmera, percorre a extensão dessa praia e mostra-a ao leitor-espectador, como numa tela de cinema. É possível afirmar que são os movimentos desse narrador-espectador - ou, mais precisamente, narrador-voyeur(11) - os principais elementos a dar forma ao conto.

o texto é composto apenas por um longo parágrafo, mas, ao contrário do que se poderia supor, o ritmo não é lento. Os períodos curtos conferem ao conto um dinamismo que encontra analogia nos movimentos de câmera. O que se observa é uma sucessão de planos de duração curta ou intermediária, como é possível perceber no trecho a seguir, que inicia a narrativa:

Havia uma mulher gorda, vermelha, descascada, cheia de bolhas nas costas, cobrindo as pernas gordas com uma toalha toda suja de areia. Havia o marido da mulher gorda, que parecia olhar para o mar, mas estava mesmo era olhando para o vazio, com uma barriguinha, a barba por fazer, olheiras bem fundas e um órgão sexual enrugado e minúsculo(12). 
A citação anterior se assemelha a outros momentos do conto, em termos estruturais. Percebe-se que há uma oscilação entre o plano médio e o plano de detalhe: ora o olhar-câmera do narrador capta as personagens a certa distância, permitindo situá-las no espaço, ora capta detalhes que somente um closepoderia discernir. As bolhas nas costas, a barba por fazer, as olheiras e o órgão sexual são elementos que somente podem ser mostrados por meio da aproximação da câmera. À exibição desses detalhes, sucede uma tomada um pouco mais afastada, que permite vislumbrar uma mulher gorda na praia ou o seu marido olhando para o mar (ou para o vazio).

Neste ponto, é válido mencionar que, apesar de voyeur, o narrador não se furta a tirar conclusões ou a inserir suas impressões sobre aquilo que narra. Sobre a ficção de João Gilberto Noll, Oliveira afirma que, conforme a tendência da literatura contemporânea, é freqüente "tomar-se o próprio olhar como objeto da narração"(13). Entretanto, não deixa de salientar o fato de que qualquer narrativa envolve as "concepções e curiosidades" daquele que narra. Inferir que o marido da gorda olha para o vazio e não para o mar pode ser uma maneira de preparar para um final que, ao longo do texto, é construído com doses de ironia e melancolia. Assim, o plano de detalhe, amplamente utilizado em "Aquarius", possui um papel situado entre o destaque de determinado objeto no enredo e a tentativa de desdramatizar o texto, dotando a palavra de maior poder imagético, como sucede na produção de Noll.

Em alguns momentos, o narrador lança mão de planos de conjunto, como no trecho em que volta seu olhar para os vendedores de bebidas na praia:

Havia o pessoal que morava na cidade daquela praia, que aproveitava aquele verão para vender bebida alcoólica, naquela praia do saco de batata chips e da música que estimulava os ouvintes a ficar pensando em comer ou dar as bocetas, lá, admirando as bundas das mulheres de porrezinho, os seios firmes das adolescentes que pensavam em sexo, os músculos dos caras fortes e a modernidade dos executivos de férias. (14)

Em princípio, percebe-se que, focando "o pessoal que morava na cidade daquela praia", o narrador utiliza um plano de conjunto. Entretanto, o olhar da câmera não permanece estático e é lançado para todo o contexto da praia. Isso colabora para que o cenário assuma uma dinâmica incessante e a praia adquira uma feição agitada: o close no saco de batata chips, as bundas das mulheres, os seios das adolescentes, os músculos dos caras fortes e os executivos de férias são captados em pleno movimento. Há nesse trecho, ainda, um elemento bastante significativo, no que se refere à apropriação de recursos cinematográficos: a sonorização. O texto, como o filme, passa a ser dotado de som. No caso específico do conto de André 
Sant'Anna, o efeito de sonorização se concentra em uma música "que estimulava os ouvintes a ficar pensando em comer ou dar as bocetas". Quando a música é mencionada, imediatamente a praia se torna sonorizada: "a música de verão que tocava na barraquinha" permanece nos ouvidos das personagens e também nos do leitor que, por sua vez, estão subordinados aos ouvidos do narrador.

Observa-se que a ironia persiste em ambos os excertos. É como se, num refrão, o narrador preparasse o campo para o desfecho: "Havia toda essa gente e mais um monte de gente igual a essa gente das bundas, dos músculos, das barriguinhas e dos olhares que olhavam para o vazio, ao som daquela música das bundas e da garrafa. Havia toda essa gente entrando para o Terceiro Milênio"(15). O olhar do narrador não é vazio de senso crítico e a melancolia que ele assume sinaliza um descrédito diante do futuro das personagens inseridas na realidade narrada. É nítido o uso do travelling no desfecho do conto. Com - travelling para trás, o narrador confere, sobretudo, um sentido conclusivo ao texto. Entretanto, conforme Marcel Martin, o travellingpara trás pode ter vários sentidos(16). Dos cinco sentidos enumerados por Martin, dois deles parecem relevantes para o final de "Aquarius": o primeiro, já mencionado, é o de conclusão; o outro é o que produz a impressão de desânimo e impotência. Dessa forma, pode-se afirmar que o movimento final do olhar-câmera desse narrador oferece ao leitor a conclusão sob uma mirada pessimista, que admite a impotência e a ausência de perspectivas daquelas personagens que entram para o Terceiro Milênio.

\section{Sexo e a montagem de fragmentos}

No primeiro capítulo do romance Sexo, todos os protagonistas encontram-se no shopping center e em suas proximidades, focalizados, primeiramente, dentro de um elevador, para, em seguida, dispersarem-se. Ao longo do romance, são narradas cenas em que cada uma dessas personagens apresentadas protagoniza relações sexuais. A seqüência da narrativa pode, inicialmente, frustrar expectativas, visto que a ação não transcorre de maneira teleológica, restringindo-se o narrador a descrever as minúcias do ato sexual entre as personagens. As cenas se configuram como fragmentos, agrupados sem a necessidade de seguirem uma ordem causal e, talvez, passíveis de serem superpostos.

- capítulo em foco corresponde ao momento da narrativa em que se narram as relações praticamente idênticas entre dois Jovens Executivos e suas respectivas Noivas Louras, Bronzeadas Pelo Sol. Após tentativas frustradas de incrementar as relações sexuais com suas noivas, os Jovens Executivos rompem os seus noivados, o que culmina com a troca de parceiras. Todas as 
personagens envolvidas nessa cena têm as mesmas preferências, as mesmas leituras e as mesmas fantasias, além de partilharem dos mesmos destinos. É relevante pontuar que a estrutura do texto é a mesma para ambos os executivos, mudando apenas o nome das personagens (o que se resume a um detalhe na cor das gravatas). Em um parágrafo, transcrito parcialmente a seguir, resumem-se o namoro, o noivado, o casamento e a lua-de-mel das personagens, sucedendo o mesmo com ambos os Jovens Executivos:

O Jovem Executivo De Gravata Azul Com Detalhes Vermelhos namorou a Noiva Loura, Bronzeada Pelo Sol, Do Jovem Executivo De Gravata Vinho Com Listras Diagonais Alaranjadas. [...] O Jovem Executivo De Gravata Azul Com Detalhes Vermelhos ficou noivo da Noiva Loura, Bronzeada Pelo Sol, Do Jovem Executivo De Gravata Vinho Com Listras Diagonais Alaranjadas. O Jovem Executivo De Gravata Azul Com Detalhes Vermelhos se casou com a Noiva Loura, Bronzeada Pelo Sol, Do Jovem Executivo De Gravata Vinho Com Listras Diagonais Alaranjadas. [...] passaram a lua de mel no hotelzinho the best, na Normandia, indicado pelo Executivo De Óculos Guest. [...](17)

Um primeiro ponto a ser destacado, na passagem anterior, é o fato de que praticamente todo o texto de sexo pode ser compreendido como um conjunto de notações de cena. As frases são curtas e objetivas (apenas os nomes das personagens parecem sugerir que o texto é longo e vagarosol e são carregadas de valor imagético. O ritmo veloz é, assim, um traço marcante do romance de André Sant'Anna. Ao descrever cenas de sexo, o narrador se aproxima da estrutura de um filme pornográfico. Não obstante, o texto é tão desdramatizado quanto o de "Aquarius" e sua finalidade não é a excitação suscitada pela pornografia.

Observa-se também que as personagens são descritas muito parcamente, portando somente seus elementos mais indispensáveis: no caso específico, as cores das gravatas e os caracteres físicos mais marcantes são responsáveis pela identificação das personagens. A narrativa assume um tom de provisoriedade que a aproxima muito da função do roteiro, que deve ser desenvolvido na etapa da filmagem.

Por outro lado, é evidente a minúcia com que o narrador detalha as cenas de sexo, aproximando bastante o seu olharcâmera dos corpos das personagens:

O Jovem Executivo De Gravata Azul Com Detalhes Vermelhos tirou o sutiã de sua Noiva Loura, Bronzeada Pelo Sol. A Noiva Loura, Bronzeada Pelo Sol, Do Jovem Executivo De Gravata Vinho Com Listras Diagonais Alaranjadas tinha seios firmes com róseos mamilos. (18)

O narrador-voyeur se vale dos planos médios e dos planos de detalhe para percorrer os corpos e os órgãos sexuais. Como no filme pornográfico, o olhar oscila entre a captação de 
detalhes dos corpos e a abrangência de parte maior do corpo, individualizando as personagens. O detalhamento atingido quando se lança mão desses planos confere ao texto de André Sant'Anna um realismo comparado ao da imagem plasmada na tela do cinema. É como se o leitor fosse também espectador privilegiado da relação sexual entre os Jovens Executivos e suas respectivas Noivas Louras.

A passagem anterior permite observar o uso de outro recurso cinematográfico: a cromatização. De acordo com Oliveira, "a descrição de peças da indumentária usada pelos personagens e de alguns objetos que se oferecem ao olhar do narrador, além de atender a um detalhamento roteirístico, auxilia nesse processo de cromatização"(19). As cores exercem, em Sexo, uma função bastante significativa: mais imediatamente, é através delas que os dois Jovens Executivos são diferenciados. Além disso, há a preocupação com o detalhamento de certos aspectos do corpo cuja notoriedade não poderia passar em branco: os mamilos róseos, os cabelos louros e a pele bronzeada têm um papel na narrativa que excede a mera caracterização das personagens e permite que o leitor veja o estilo de vida daqueles indivíduos.

A despeito da pluralidade de técnicas cinematográficas que o capítulo apresenta, a montagem predomina sobre as demais. Eis - que confere ao texto de André Sant'Anna um dinamismo e uma plasticidade que o cinema exibe com desenvoltura. Conforme Oliveira, embora o procedimento de montagem não seja exclusivo do cinema, é considerado como o de maior especificidade dessa linguagem. Como sucede aos filmes, Sexoé composto de cenas montadas pelo narrador. As várias mudanças de plano dotam o texto de uma agilidade que possibilita a leitura rápida, assim como os filmes têm seu tempo de exibição pré-determinado. A repetição das cenas por personagens diferentes é algo que deixa patentes, nesse capítulo, o procedimento de montagem e a consciência de que essa realidade é uma construção de linguagem:

\footnotetext{
O Jovem Executivo De Gravata Vinho Com Listras Diagonais Alaranjadas falava palavrões enquanto fazia sexo anal com sua Noiva Loura, Bronzeada Pelo Sol. O Jovem Executivo De Gravata Azul Com Detalhes Vermelhos falava palavrões enquanto fazia sexo anal com sua Noiva Loura, Bronzeada Pelo Sol.(20)
}

Todo o capítulo é construído segundo essa estrutura, narrando simultaneamente as ações dos dois Jovens Executivos e suas Noivas Louras. O processo de montagem utilizado para produzir - efeito de simultaneidade é denominado montagem paralela. O seu uso freqüente ao longo de um capítulo inteiro reforça a fragmentação da narrativa, algo já provocado pelos cortes recorrentes, pelas inúmeras mudanças de plano. Assim, o enredo 
não pode ser reconstruído linearmente, pois os planos se colam uns aos outros: são fragmentos simultâneos, recortados e colados, o que remete às técnicas de cópia e colagem, tão caras à arte pop.

\section{Considerações finais}

Em Seis propostas para o próximo milênio(21), Italo Calvino reúne cinco conferências apresentadas na Universidade de Harvard, em que expõe alguns valores da literatura que considera relevantes e os situa no contexto do próximo milênio - já iniciado com o século atual. Seriam seis os valores, mas - texto ficou incompleto e composto apenas pelas cinco seguintes qualidades: leveza, rapidez, exatidão, visibilidade e multiplicidade.

Em relação à literatura pop contemporânea, pode-se afirmar que todas essas qualidades estejam presentes, o que não é feito sem ressalvas. Primeiramente, porque o texto de Calvino é uma reflexão sobre seu próprio fazer literário. Por outro lado, não se trata de um manual para os escritores do século 21, tampouco um elenco de traços passíveis de encontrar, de maneira exata e rigorosa, nos textos pop contemporâneos. Em suma, as qualidades expostas por Calvino não se prestam a fazer parte de uma categorização que objetive o enrijecimento das fronteiras existentes no campo da literatura ou dos limites entre esta e outras artes.

Talvez seja possível pensar sobre esses valores em conjunto nos textos contemporâneos. Leveza, rapidez, exatidão, visibilidade e multiplicidade são aspectos que se imbricam e compõem a tessitura das narrativas pop contemporâneas. No entanto, a despeito dos outros, dois traços são emblemáticos para a relação entre cinema e literatura e foram explorados a partir da prosa de André Sant'Anna: rapidez evisibilidade.

Para se adjetivar um texto em prosa como cinematográfico, não lhe basta apenas a alusão ao cinema (como há na literatura pop e em outros textos). É necessário mais: como afirma Oliveira acerca de Noll, é preciso buscar, por meio da técnica narrativa, "projetar a imagem diretamente na página do livro"(22). Eis o que sucede com "Aquarius" eSexo. Nos textos de Sant'Anna, rapidez e visibilidade combinam-se para dar corpo a narrativas que podem ser lidas com a rapidez de quem assiste a um filme na sala de cinema. Como afirma Calvino,

... numa época em que outros media triunfam, dotados de uma velocidade espantosa e de uma raio de ação extremamente extenso, arriscando reduzir toda comunicação a uma crosta uniforme e homogênea, a função da literatura é a comunicação entre o que é diverso pelo fato de ser diverso, não embotando mas antes exaltando a diferença, segundo a vocação própria da escrita.(23) 
Percebe-se que uma sugestão de Calvino para a literatura do próximo (o atual) milênio é incidir na diferença, na comunicação entre o que é diverso. Se a literatura pop põe em prática o que é teorizado nas seis propostas..., não se pode confirmar cartesianamente. Mas é plausivel afirmar que as intensas trocas e mesclas entre as diversas formas de arte aqui, o cinema e a literatura - sugerem que a apropriação das técnicas cinematográficas pela literatura são também uma maneira de se apossar da velocidade com que os media contemporâneos comunicam, o que é patente nos textos de André Sant'Anna.

O modo como se desenvolve a quarta qualidade mencionada por Calvino - a visibilidade - parece depender, na literatura pop contemporânea, do reconhecimento da necessidade de incorporar recursos de outras artes. Para se inserir em um contexto em que $O$ indivíduo é bombardeado por imagens, a literatura precisa enfrentar um risco: o de perder a capacidade de suscitar "visões de olhos fechados". Tal enfrentamento se dá exatamente pela sua associação com os novos media, fato que ocorre desde o começo do século 20.

Atenuar as suas fronteiras e permitir que a tela invada a página é o que a literatura, sobretudo a pop, produzida a partir dos anos 90, tem realizado de maneira intensa. A prosa de André Sant'Anna, utilizando os recursos cinematográficos, apresenta-se como um texto veloz e imagético, como um filme em curso na tela branca das páginas. É provável que a pedagogia da imaginação, sugerida por Italo Calvino, sirva - consciente ou inconscientemente - de ponto de partida para muitos dos escritores pop na pós-modernidade. O texto desierarquizado, multíplice: a literatura pop abarca tanto a linguagem escrita quanto a linguagem visual e, não raro, a expressão verbal é suplantada pela potência imagética do texto. Como afirma Calvino: "seja como for, as soluções visuais continuam a ser determinantes, e vez por outra chegam inesperadamente a decidir situações que nem as conjecturas do pensamento nem os recursos da linguagem conseguiriam resolver"(24).

\section{Abstract}

The fusion of languages and references is remarkable in pop literary discourse. Taking as subject André Sant'Anna's post-modern pop text, it's possible to see how cinematographic strategies are used in the creative process of the narratives Aquarius, a short-story published in Amor e outras histórias, and Sexo, Sant'Anna's subsequent novel. Based on the researches by Marinyze Prates de Oliveira about João Gilberto Noll's fiction, and on the systematizing of the uses of cinematographic strategies in contemporary literature, it's possible to state that André Sant'Anna's pop prose is marked by the presence of narrative strategies of cinema.

Key Words: pop literature, cinema, André Sant'Anna. 


\section{Notas}

[1] EPSTEIN, 1991.

[2] OLIVEIRA, 2002, p. 13.

[3] OLIVEIRA, 2002, p. 15.

[4] OLIVEIRA, 2002, p. 31.

[5] HOISEL, 1980 .

[6] HOISEL, 1980, p. 141

[7] CRUZ, 2003.

[8] OLIVEIRA, 2002.

[9] SANT'ANNA, $2001 \mathrm{a}$.

[10] SANT'ANNA, $2001 \mathrm{~b}$.

[11]Referência à definição do narrador pós-moderno por Silviano Santiago, segundo a qual o narrador é aquele que extrai a si mesmo da ação narrada, configurando-se como um voyeur.

[12] SANT' ANNA, $2001 \mathrm{a}, \mathrm{p} .103$.

[13] OLIVEIRA, $2002, \mathrm{p} .81$.

[14] SANT' ANNA, $2001 \mathrm{a}, \mathrm{p} .105$.

[15] SANT'ANNA, $2001 \mathrm{a}, \mathrm{p} .107$.

[16] MARTIN, 1990, p. 48.

[17] SANT' ANNA, 2001b, p. 125.

[18] SANT'ANNA, 2001b, p. 111.

[19] OLIVEIRA, 2002, p. 122.

[20] SANT'ANNA, $2001 \mathrm{~b}, \mathrm{p} .117$.

[21] CALVINO, 1990.

[22] OLIVEIRA, $2002, \mathrm{p} .73$.

[23] CALVINO, $1990, \mathrm{p} .58$.

[24] CALVINO, 1990, p. 106.

\section{Bibliografia}

CALVINo, Italo. Seis propostas para o próximo milênio: lições americanas. Tradução de Ivo Barroso. São Paulo: Companhia das Letras, 1990.

CRUZ, Décio Torres. O pop: literatura, mídia e outras artes. Salvador: Quarteto, 2003.

EPSTEIN, Jean. O cinema e as letras modernas. Tradução de Marcelle Pithon. In: XAVIER, Ismail (Org.). A experiência do cinema. Rio de Janeiro: Graal, 1991. p. 269-275.

HOISEL, Evelina. Supercaos: estilhaços da cultura em PanAmérica e Nações Unidas. Rio de Janeiro: Civilização Brasileira, 1980 . p. 134-153.

MARTIN, Marcel. A linguagem cinematográfica. São Paulo: Brasiliense, 1990.

OLIVEIRA, Marinyze Prates de. E a tela invade a página: laços entre literatura, cinema e João Gilberto Noll. Salvador: SCT, FUNCEB, EGBA, 2002.

SANT'ANNA, André. Amor e outras histórias. Lisboa: Cotovia, 2001.

SANT'ANNA, André. Sexo. Rio de Janeiro: 7 Letras, 2001. 